\title{
Nano-morphological, Magnetic and Structural Properties of Ni Films Prepared by RF-sputtering
}

\author{
Thawatchai Chanthong ${ }^{1}$, Watcharee Rattanasakulthong ${ }^{1, *}$, Supree Pinitsoontorn ${ }^{2}$, \\ and Aphichart Rodchanarowan ${ }^{3}$
}

1 Department of Physics, Faculty of Science, Kasetsart University, Bangkok 10900, Thailand

2 Department of Physics, Faculty of Science, Khon Kaen University, Khon Kaen 40002, Thailand

3 Department of Materials Engineering, Faculty of Engineering, Kasetsart University, Bangkok 10900,

Thailand

E-mail: fsciwrr@ku.ac.th*

\begin{abstract}
Sputtered Ni Films with various deposited times (30, 60, 90,120 and 150 min.) were prepared on glass substrate by RF-sputtering in Argon gas to study effects of sputtering time on their morphological, magnetic and thermal properties. Surface morphological of $\mathrm{Ni}$ films were investigated by AFM. The AFM images show a small variation of surface roughness with sputtering time. Average surface roughness of $\mathrm{Ni}$ films over scan area of $1 \mu \mathrm{m} \times 1 \mu \mathrm{m}, 5 \mu \mathrm{m} \times 5 \mu \mathrm{m}$ and $10 \mu \mathrm{m} \times 10 \mu \mathrm{m}$ are about $0.57,1.64$ and $2.49 \mathrm{~nm}$, respectively. The AFM result infers that Ni films prepared by RF-sputtering exhibit surface roughness in order at nano-scale and have smoother surface than that prepared by DC-sputtering [1]. Structure of Ni films was characterized by XRD. The results display that Ni films exhibit a broad peak of $\mathrm{Ni}$ (FCC) phase in (111) plane with a hump at $2 \theta=23^{\circ}[1,2]$. Intensity of $\mathrm{Ni}(111)$ peak is increased with increasing sputtering time. Magnetic property of Ni films was study by VSM. The VSM results confirm that Ni films deposited for 90-150 min have a ferromagnetic phase and saturation magnetization is increased whereas coercive field is practically kept constant with increasing deposited time $[3,4]$. The DTA result of Ni films show an exothermic peak at $850^{\circ} \mathrm{C}$ corresponding to decomposition of $\mathrm{Ni}$ atoms from the glass substrate. The results confirm that surface roughness, magnetic and structural properties Ni films prepared by RF sputtering can be improved by an appropriate deposited time.
\end{abstract}

Keywords: RF-sputtering, Ni films, morphology, magnetic properties.

ENGINEERING JOURNAL Volume 16 Issue 3

Received 22 November 2011

Accepted 3 March 2012

Published 1 July 2012

Online at http://www.engj.org/

DOI:10.4186/ej.2012.16.3.71 


\section{Introduction}

Nickel films have been widely investigated by many researchers [1-4]. This magnetic film was prepared by many methods such as RF- sputtering [3], DC-magnetron sputtering [1, 2, 4] and thermal and UHV deposition in a MBE system [5]. Sputtered Ni film and its composites with a high conductivity and dielectric constant were researched to be an electromagnetic interference shielding layers. In addition, $\mathrm{Ni}$ materials with a high temperature coefficient and theirs temperature dependence on resistance are also considered the flow speed sensors in aeronautic applications. It is well known that structure of $\mathrm{Ni}$ films deposited on amorphous substrates is generally FCC phase with (111) preferred direction and it is difficult to prepare Ni films with other orientations. To achieve the suitable structures for applications, sputtering method with different deposition conditions has been widely used to prepare $\mathrm{Ni}$ films on various substrates including glass, $\mathrm{Si}(100), \mathrm{GaAs}(011), \mathrm{SiO} 2 / \mathrm{Si}$ (100) and $\mathrm{MgO}(001)$. In this research, morphological, magnetic, electrical and thermal properties of sputtered $\mathrm{Ni}$ films on glass substrate with various sputtering times were studied to achieve an appropriate deposited time for magnetic sensing applications.

\section{Experimental Procedure}

$\mathrm{Ni}$ films with different sputtering times $(30,60,90,120$ and $150 \mathrm{~min})$ were deposited on glass substrates by the RF sputtering technique in argon atmosphere. The sputtering machine (Leybold-Heraeus, Univex 300) has a cylindrical chamber of $29.5 \mathrm{~cm}$ in diameter and 31.5 in height. A Ni target $(99.99 \%)$ with diameter of 3.00 inch and thickness of 0.250 inch was located $45 \mathrm{~mm}$ away from the glass substrates inside the vacuum chamber. Before the deposition process, a glow discharge process was used to clean glass substrates. The base pressure in the vacuum chamber and the argon pressure during the deposition were $5 \times 10^{-5} \mathrm{mbar}$ and $1 \times 10^{-3} \mathrm{mbar}$, respectively. The sputtering process was carried with constant RF power of $200 \mathrm{~W}$ and rate flow of argon gas was around $51 \mathrm{sccm}$. The morphology of the sputtered Ni films was studied by atomic force microscopy (Asylum Research, MFP-3D (Bio)) with various scanning sizes in contact mode. Structural and thermal properties of sputtered films were characterized by X-ray diffractometry (Bruker, D8 Advance) and differential thermal analysis (Perkin Elmer, DTA 7) with heating rate of $40{ }^{\circ} \mathrm{C} / \mathrm{min}$, respectively. Electrical resistance of the films was measured by van der Pauw method. Hysteresis loops of $\mathrm{Ni}$ films were studied at room temperature by vibrating sample magnetometer (Lekeshore, 7400) with two geometries of measurements under magnetic field of $10 \mathrm{kOe}$. To measure in-plane hysteresis, the magnetic field was applied parallel to the film's surface. For the perpendicular hysteresis loops, the magnetic field was applied normal to the surface of the films. Magnetic parameters such as coercive field $\left(\mathrm{H}_{\mathrm{c}}\right)$, remanent magnetization $\left(M_{r}\right)$, saturation magnetization $\left(M_{s}\right)$ and squareness $\left(M_{r} / M_{s}\right)$ were then derived from the hysteresis loops. The $\mathrm{H}_{\mathrm{c}}$ was determined from the $\mathrm{x}$-intercept of the loop whereas the $\mathrm{y}$-intercept corresponded to the $\mathrm{M}_{\mathrm{r}}$. A ratio of remanent magnetization to saturation magnetization is referred as the squareness.

\section{Results and Discussion}

\subsection{Surface Roughness}

Figure 1 shows AFM images of Ni films with different sputtering times over scanning areas of $1 \mu \mathrm{m} \times 1 \mu \mathrm{m}$. Surface morphology exposes that sputtered $\mathrm{Ni}$ films have an island structure with various shape, size and distribution. The columnar shapes were evidently observed in a $30-\mathrm{min}$ Ni film while a $150-\mathrm{min}$ Ni film exhibited the smaller and shorter columns. The 60, 90, and 120-min Ni films showed the granular structure with different sizes. The smallest size of granular structure and the lowest roughness were observed in 90min Ni film. For 60-min Ni film, morphological structure is composed of the biggest size of granular grains with the wide-ranging size distribution. From the morphological results, it can be concluded that the 90min Ni film has a smoothest surface area with a regular roughness. The results reveal that morphological structure can be modified by sputtering time. In our preparation, sputtering process can be divided into 3 stages. At the first stage of the deposition process, the atoms deposited on glass were agglomerated and then elongated of grains in columnar structure. In the middle stage, the columnar grains were decomposed into granular structure and then reached to final stage. In the final stage, the deposited atoms initially start to agglomerate into columnar structure again. 

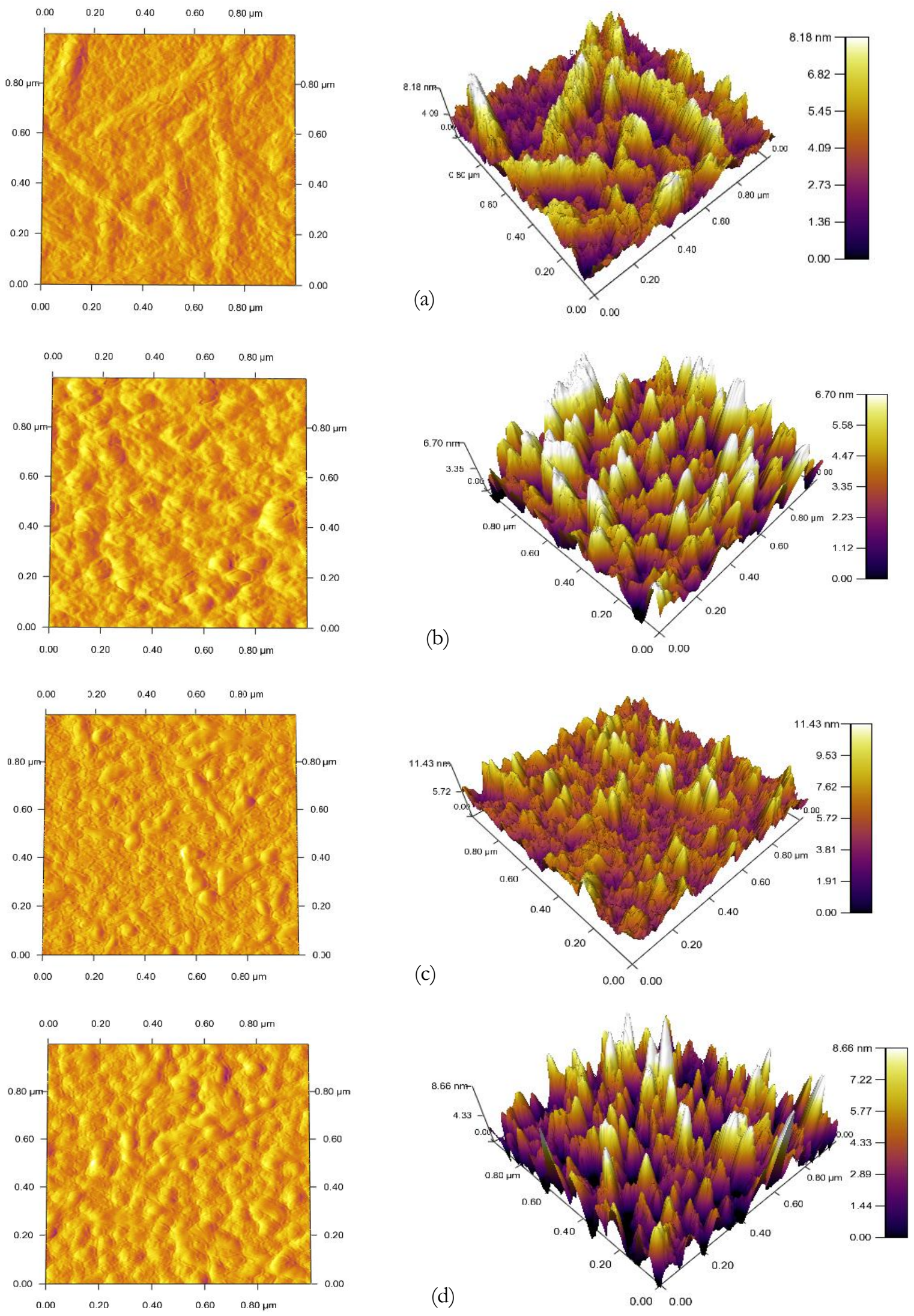

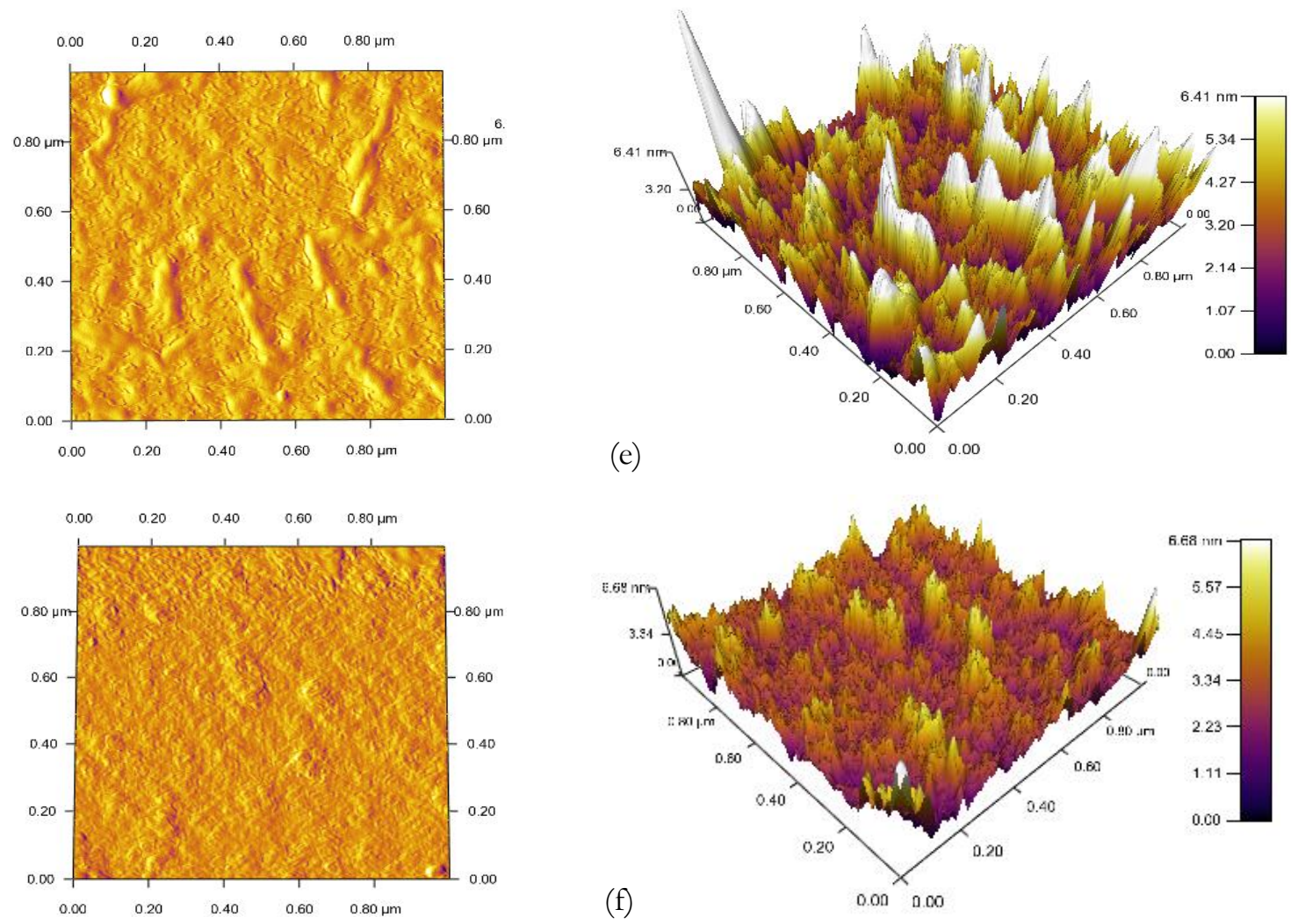

Fig. 1. AFM results of Ni films sputtered for (a) $30 \mathrm{~min}$, (b) $60 \mathrm{~min}$, (c) $90 \mathrm{~min}$, (d) $120 \mathrm{~min}$, and (e) 150 min were compared to that of $(f)$ glass substrate.

In comparison to the glass substrate, morphological structure of glass substrate was consisted of very fine granular shapes with a surface roughness $\left(\mathrm{R}_{\mathrm{a}}\right)$ of $0.249 \mathrm{~nm}$ and 1.45 corresponding to $1 \mu \mathrm{m} \times 1 \mu \mathrm{m}$ and $10 \mu \mathrm{m} \times 10 \mu \mathrm{m}$ scan areas, respectively. The variations of surface roughness of sputtered $\mathrm{Ni}$ with sputtering time were plotted as in Fig. 2. The 90 -min Ni film shows the highest roughness of $0.552 \mathrm{~nm}$ over scan area of $1 \mu \mathrm{m} \times 1 \mu \mathrm{m}$ and the lowest roughness of $1.52 \mathrm{~nm}$ over scan area of $10 \mu \mathrm{m} \times 10 \mu \mathrm{m}$. This result confirms the smoothest surface with regular roughness in the large area of the $90-\mathrm{min} \mathrm{Ni}$ film on the glass substrate as a result of a smallest granular grain size in middle stage of deposition process. The 60 -min Ni film has a high surface roughness of $2.13 \mathrm{~nm}$ and the 120-min Ni film exhibits the highest roughness of $2.27 \mathrm{~nm}$ over scan area of $10 \mu \mathrm{m} \times 10 \mu \mathrm{m}$. These results are corresponding to the end of first state and the initial of final stage, respectively. It can be concluded that the surface roughness of sputtered $\mathrm{Ni}$ films significantly depend on sputtering time. In this work, Ni film deposited for 90 min shows the smoothest surface with regular roughness. 


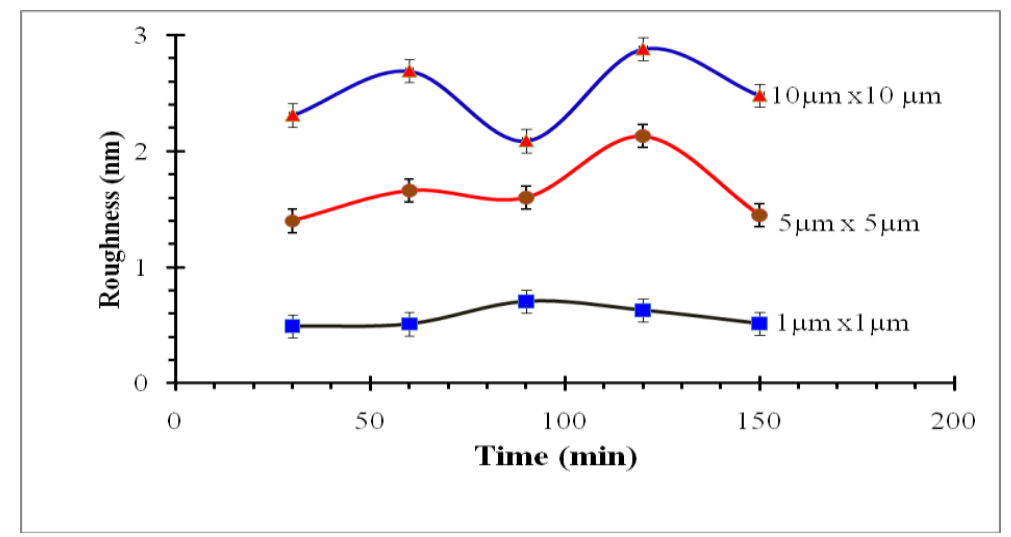

Fig. 2. Surface roughness of $\mathrm{Ni}$ films is deposited for $30 \mathrm{~min}, 60 \mathrm{~min}, 90 \mathrm{~min}, 120 \mathrm{~min}$, and $150 \mathrm{~min}$ with different scanning areas.

\subsection{Structural, Electrical and Thermal Properties}

Structural properties of Ni films were characterized by XRD shown in Fig. 3. XRD results confirm that Ni films exhibit a broad peak of $\mathrm{Ni}$ (FCC) phase in (111) plane with a hump at $2 \theta=23^{\circ}$ indicating the amorphous phase of glass substrate $[1,2]$. Intensity of $\mathrm{Ni}(111)$ peak is increased with increasing sputtering time. It can be defined that the thickness of $\mathrm{Ni}$ films is increased with deposited time and low intensity of $\mathrm{Ni}$ (111) peak signifying the thinness of the Ni films. No Ni peaks is observed in 30-min Ni film. It implies that $\mathrm{Ni}$ film cannot be prepared in our sputtering system at power of $200 \mathrm{~W}$ with sputtering time of $30 \mathrm{~min}$ or less than this deposited time or the thickness of 30 -min Ni film is very thin to be detected by XRD. The variation of the sputtered $\mathrm{Ni}$ film resistance as a function of the deposited times is shown in Fig. 4. Electrical resistance of $\mathrm{Ni}$ films is decreased with increasing sputtering time. The 60-min $\mathrm{Ni}$ film has the highest electrical resistance of about $1187 \Omega$ whereas the others films have a lower electrical resistance. For 90, 120 and 150-min $\mathrm{Ni}$ films, the resistance are about 232, 225 and $246 \Omega$, respectively. From the resistance result of $\mathrm{Ni}$ films, it can be understood that the decrease of film resistance is due to the increase of film thickness with increasing sputtering time.

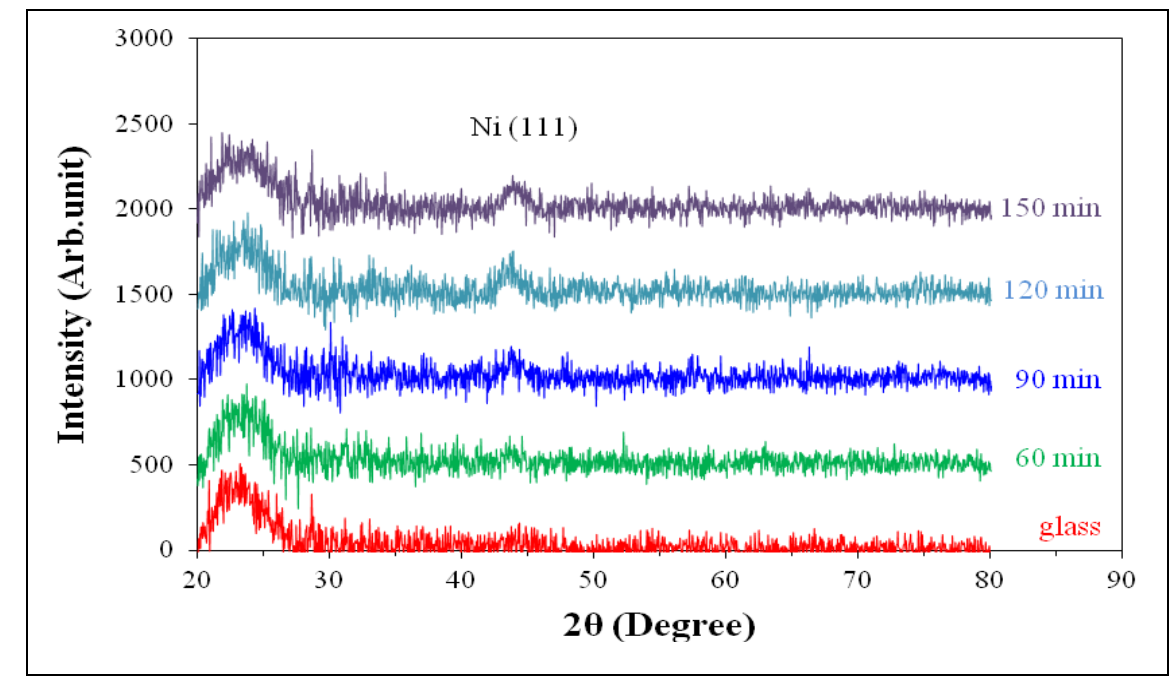

Fig. 3. XRD results of sputtered Ni films with different deposited times. 


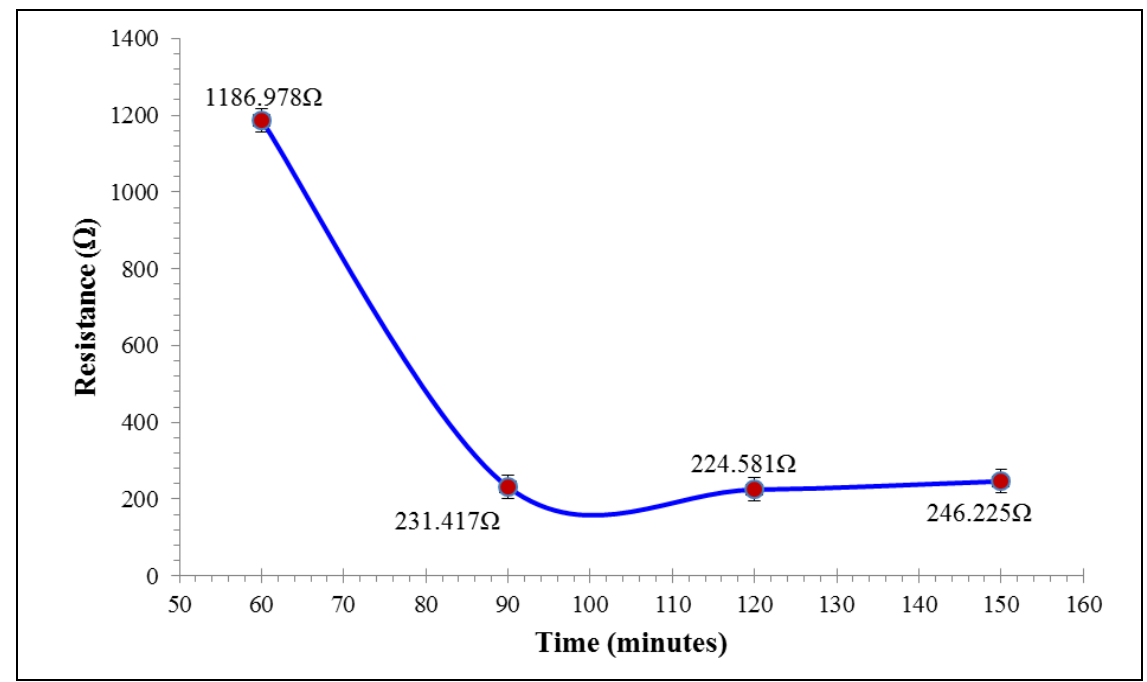

Fig. 4. Electrical resistance of sputtered Ni films with different deposited times.

DTA results of sputtered $\mathrm{Ni}$ films are plotted in Fig. 5. The operating temperature range is from $200{ }^{\circ} \mathrm{C}$ to $1200{ }^{\circ} \mathrm{C}$ with heating rate of $40{ }^{\circ} \mathrm{C} / \mathrm{min}$. All Ni films exhibit a broad exothermic peak around $800{ }^{\circ} \mathrm{C}$ and a modest endothermic peak at around $570{ }^{\circ} \mathrm{C}$. The major exothermic peak is possible due to the release of energy by the segregation of $\mathrm{Ni}$ atoms from the glass substrate and the lattice recovery process. The $90-\mathrm{Ni}$ film has a maximum peak area indicating a highest heat release from the decomposition process. It can be described that the release of heat in decomposition and lattice recovery is due to the lowest roughness and regular grain size of this film. On the other hand, the highest heat release is observed because of the tightfisted interface between $\mathrm{Ni}$ films and glass substrate. For the endothermic peak at around $570{ }^{\circ} \mathrm{C}$, the heat is absorbed corresponding to the melting temperature of $\mathrm{Ni}_{2} \mathrm{O}_{3}$. In addition to these peaks, the 90,120 and $150-$ min $\mathrm{Ni}$ films show other endothermic peak at around $350^{\circ} \mathrm{C}$ but the $60-\mathrm{min} \mathrm{Ni}$ films displays a minor exothermic peak at around $400{ }^{\circ} \mathrm{C}$. For these endothermic peaks, heat absorption gives rise to the reduction of defects and dislocations. The minor exothermic peak of the 150-min Ni film is obtained at around $400{ }^{\circ} \mathrm{C}$ corresponding to the lattice recovery process.

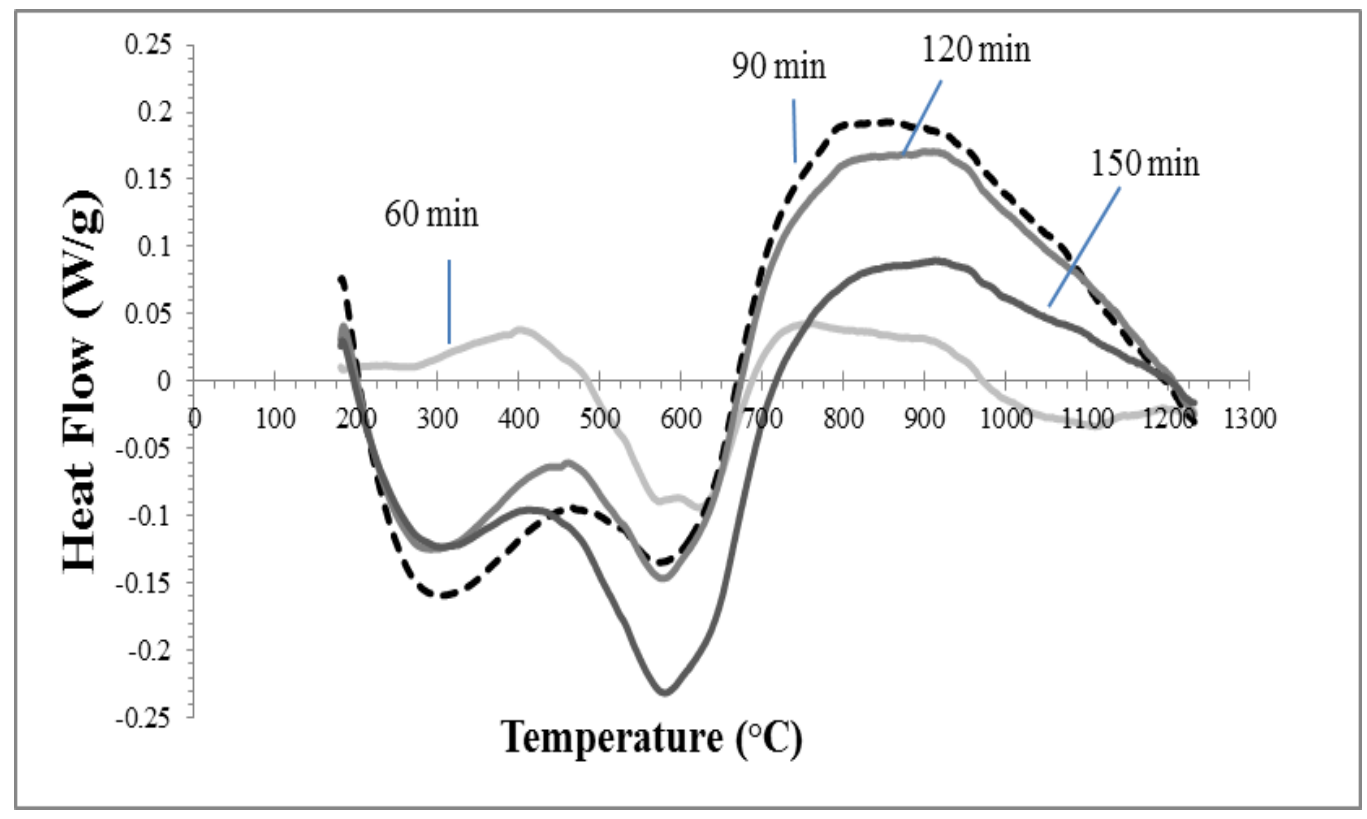

Fig. 5. DTA results of Ni films with different sputtering times. 


\subsection{Magnetic Properties}

Table 1. Magnetic parameters of the sputtered Ni films deposited at room temperature.

\begin{tabular}{cccccccccc}
\hline \multirow{2}{*}{$\begin{array}{c}\text { Time } \\
(\mathbf{m i n})\end{array}$} & $\begin{array}{c}\mathbf{H}_{\mathbf{c}} \\
\mathbf{( O e )}\end{array}$ & $\begin{array}{c}\mathbf{M}_{\mathbf{r}} \\
\text { (Arb.unit) }\end{array}$ & $\begin{array}{c}\mathbf{M}_{\mathbf{s}} \\
\text { (Arb.unit) }\end{array}$ & $\mathbf{M}_{\mathbf{r}} / \mathbf{M}_{\mathbf{s}}$ & & $\begin{array}{c}\mathbf{H}_{\mathbf{c}} \\
\mathbf{( O e )}\end{array}$ & $\begin{array}{c}\mathbf{M}_{\mathbf{r}} \\
\text { (Arb.unit) }\end{array}$ & $\begin{array}{c}\mathbf{M}_{\mathbf{s}} \\
\text { (Arb.unit) }\end{array}$ & $\mathbf{M}_{\mathbf{r}} / \mathbf{M}_{\mathbf{s}}$ \\
\hline 60 & - & - & 0.62 & - & & - & - & 1.05 & - \\
90 & 190 & 0.53 & 5.14 & 0.102 & & 127 & 0.24 & 4.88 & 0.05 \\
120 & 193 & 0.26 & 3.27 & 0.078 & & 148 & 0.29 & 4.65 & 0.06 \\
150 & 205 & 0.30 & 3.89 & 0.077 & & 158 & 0.30 & 5.16 & 0.06 \\
\hline
\end{tabular}

M-H curves of sputtered Ni films are illustrated in Fig. 6 and Fig. 7 corresponding to perpendicular and inplane hysteresis loops, respectively. Both in-plane and perpendicular hysteresis loops imply that tendency of the saturation magnetization is remarkably raised up from thicker films. However, the $90-\mathrm{min} \mathrm{Ni}$ film shows a maximum value in perpendicular measurement and a rather high saturation magnetization in inplane measurement. The highest saturation magnetization of the 90-min Ni film agrees with AFM and DTA results that film has the lowest roughness and the highest exothermic peak area. From these results, it suggests that the saturation magnetization strongly depends on grain sizes and size distributions in Ni films. The highest saturation is observed in the $90-\mathrm{min} \mathrm{Ni}$ film because this film consists of the regular and small gran sizes. For coercive field from both in-plane and perpendicular geometries, it is slightly increased with increasing sputtering time. This small variation of coercive field coincides with the magnetic results from other researchers group [3, 4]. The squareness does not reveal the variation in in-plane measurement but it is a little decreased with sputtering time in perpendicular measurement. The magnetic parameters from hysteresis loops of sputtered Ni films are summarized in Table. 1. Magnetic results suggest that the 90-min $\mathrm{Ni}$ film has the highest saturation with a moderate coercive field. These results confirm the suitable sputtering time in our preparation of $\mathrm{Ni}$ films with a highest saturation magnetization is 90 min practically by RF-sputtering.

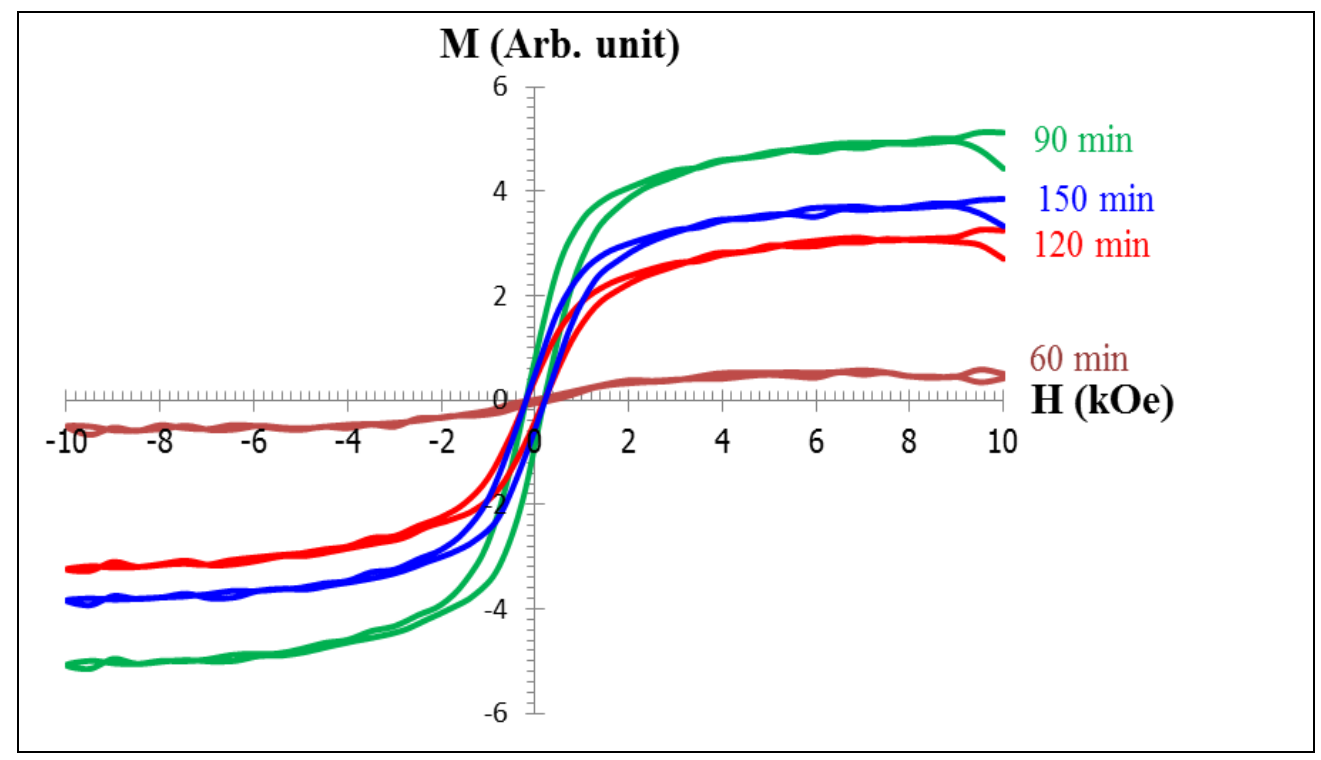

Fig. 6. Perpendicular hysteresis of Ni films with different sputtering times. 


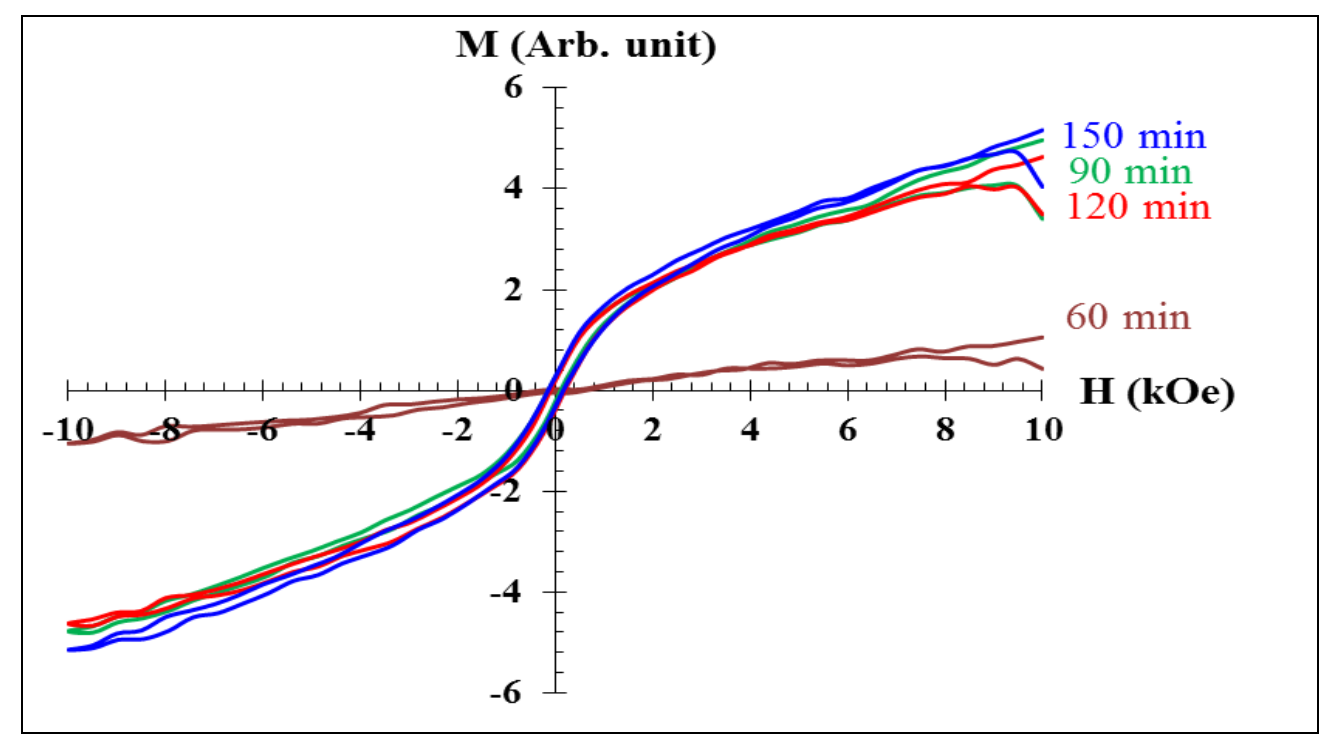

Fig. 7. In-plane hysteresis loops of Ni films with different sputtering times.

\section{Conclusions}

The sputtered $\mathrm{Ni}$ films with different deposited times (30, 60, 90,120 and $150 \mathrm{~min}$.) prepared by RFsputtering in argon atmosphere with constant RF power of $200 \mathrm{~W}$ consist of Ni (FCC) phase in (111) direction. The 90-min Ni film shows the highest saturation with a moderate coercive field and has the smoothest surface with regular roughness. The results confirm that surface roughness, magnetic and structural properties Ni films prepared by RF sputtering can be improved by a suitable deposited time and $\mathrm{Ni}$ films can be applied for magnetic sensing because of their ferromagnetic phase at room temperature.

\section{Acknowledgement}

This work was supported by National Metal and Materials Technology Center (Grant MT-B-53-MET-11231-G) and Faculty of Science, Kasetsart University.

\section{References}

[1] J. Xu, T. Shao and G. Jin, "Effect of processing conditions on microstructure and electrical characteristics of Ni thin films," Vacuum, vol. 84, pp. 478-482, Oct. 2010.

[2] X. Yu and Z. Shen, "The electromagnetic shielding of Ni films deposited on cenosphere particles by magnetron sputtering method," J. Magn. Magn. Mater., vol. 321, pp. 2890-2895, Apr. 2009.

[3] O. Kohmoto, N. Mineji, Y. Isagawa, F. Ono, and O. Kubo, "Perpendicular anisotropy of sputtered Ni films", J. Magn. Magn. Mater., vol. 239, pp. 36-38, 2002.

[4] Y. Yang, H. Qiu, X. Chen, and M. Yu, "Characteristics of $\mathrm{Ni}$ films deposited on $\mathrm{SiO} 2 / \mathrm{Si}(100)$ and $\mathrm{MgO}(001)$ by direct current magnetron sputtering system with the oblique target," A. Appl. Surf. Sci., vol. 255, pp. 6226-6231, Feb. 2009.

[5] S. A. Haque, A. Matsuo, Y. Seino, Y. Yamamoto, S. Yamada, and H. Hori, "Effect of GaAs substrate on the magnetic properties of Ni film," Physica. B., vol. 305, pp. 121-126, May 2001. 